\title{
Frozen Section Analysis of Breast Lumpectomy Margins
}

\section{Fatma Khinaifis Althoubaity, Adnan Merdad, Nouf Yahya Akeel, Nisar Haider Zaidi, Abdullah Omar Sultan}

Department of Surgery, Faculty of Medicine, King Abdulaziz University, King Abdulziz University Hospital, Jeddah, KSA

Email: drnhzaidi@hotmail.com

How to cite this paper: Althoubaity, F.K., Merdad, A., Akeel, N.Y., Zaidi, N.H. and Sultan, A.O. (2017) Frozen Section Analysis of Breast Lumpectomy Margins. Surgical Science, 8, 269-277. https://doi.org/10.4236/ss.2017.86029

Received: February 20, 2017

Accepted: June 25, 2017

Published: June 28, 2017

Copyright (c) 2017 by authors and Scientific Research Publishing Inc. This work is licensed under the Creative Commons Attribution International License (CC BY 4.0).

http://creativecommons.org/licenses/by/4.0/ (c) (i) Open Access

\begin{abstract}
Objectives: To evaluate breast lumpectomy margins by frozen section in breast conservation surgery. Methods: A retrospective study of frozen section of lumpectomy margins of one hundred ten patients was done at King Abdulaziz University Hospital from June 2007 to June 2013. All patients underwent lumpectomy + Sentinel lymph node biopsy. Patient records were studied for location of mass in breast, size of mass, site of breast, pre or postmenopausal, frozen section margins, new frozen section margins, permanent margins, reoperation. Complications like skin necrosis, numbness, and wound infection were studied. Result: Majority were Saudis (64.5\%). Left breast was involved in $60 \%$. Upper outer quadrant was involved in majority (51.9\%). Size of mass was less than $1 \mathrm{~cm}$ in $14.8 \%$ cases, $1-2.9 \mathrm{~cm}$ in $43.5 \%, 3-4 \mathrm{~cm}$ in $13 \%$, more than 4 $\mathrm{cm}$ in $10.2 \%$. Lumpectomy plus sentinel lymph node biopsy was done in $96.4 \%$ and lumpectomy and axillary lymph node dissection was done in $1.8 \%$ cases. Gross margins were positive in $17.3 \%$ and frozen margins were positive in 28.2\%. New margin on frozen section were positive in $3.6 \%$ and negative in $79.1 \%$. Permanent section histology showed positive margins in $5.5 \%$ and negative in $94.5 \%$ cases. Re-operation was done in $7.3 \%$. Lympho-vascular margins were positive in $20.9 \%$. Skin necrosis was found in $2.2 \%$, numbness was found in $4.4 \%$, wound infection was in $2.2 \%$. Conclusion: Lumpectomy margins with frozen section reduce re-operation and recurrence.
\end{abstract}

\section{Keywords}

Frozen Section, Lumpectomy, Margins, Breast Lump

\section{Introduction}

Breast cancer treatment has gone tremendous changes in recent years. Surgical treatment has shifted from mastectomy to breast conserving surgery (BCS). BCS 
has many advantages, like maintaining the shape, less mutilating, and better psychological outcome. BCS has higher local recurrence than mastectomy [1] [2]. Many factors play a role in recurrence after BCS, like tumor stage and grade, lympho-vascular invasion, molecular status and surgical margin. Positive surgical margin has 2 - 3 times chances of recurrence than negative margin [3]. Intra-operatively emphasis should be given to achieve negative margins. Frozen section analysis [FSA] is used for lumpectomy margins where freezing and sectioning of specimen is followed by thawing, fixation and staining and can be done in half an hour [4]. Other method is imprint cytology where specimen is pressed onto glass slides and making imprint of all six margins with the principle that only malignant cells adhere to slides [5]. BCS done for breast cancer and Ductal carcinoma in situ [DCIS] has positive margins from $15 \%$ to $47 \%$ [6] [7] [8] [9]. Re-excision rates range from $23 \%$ to $59 \%$ [10] [11] [12]. Previously more than $1 \mathrm{~cm}$ margins were considered safe [13] [14], but recent evidence shows equivalent rates of recurrence with $1-2 \mathrm{~mm}$ margins [15] [16]. We present our experience with lumpectomy margins and outcome.

\section{Methods}

At King Abdulaziz University Hospital, Jeddah between June 2007 to January 2013 a retrospective study of frozen section analysis of breast lumpectomy margins was done. Number of patients studied were 110. Inclusion criteria was females with breast lump over 18 years of age undergoing breast conservation surgery. Exclusion were patients undergoing modified radical mastectomy. Hospital records of Patients were studied by searching hospital information system. OPD records as well as inpatient records were studied regarding age, nationalities, menopausal status, location of mass in breast, size of mass, left or right breast mass, previous surgery or radiotherapy, radiological evaluation, type of surgery done, adjuvant or neo-adjuvant chemotherapy, gross margins, frozen section margins, new frozen section margins, permanent margins, reoperation, intra-operative radiotherapy[IOR], tumor type, lympho-vascular invasion, estrogen receptor [ER],progesterone receptor[PR], HER2, metastasis, stage of disease, tumor size, no. of lymph nodes, sentinel lymph node dissection [SLD] done. Post operative complications like skin necrosis, numbness, wound infection were studied. Operation done during this period were extensively studied for frozen section analysis of breast lumpectomy margins. Patients were followed for two years. This study was approved by hospital ethical committee. Statistical analysis was done using SPSS.

\section{Results}

Majority of patients were Saudis (64.5\%), and rest were from different nationalities like Yemeni, Egyptians, Palestinian, Syrians, and Jordanians (Figure 1). There was history of previous surgery in $9.1 \%$. Menopausal status was studied and majority of our patients were post-menopausal (56.4\%) and Pre menopausal were $43.6 \%$ (Figure 2). In majority of cases left breast was involved (60\%) and 


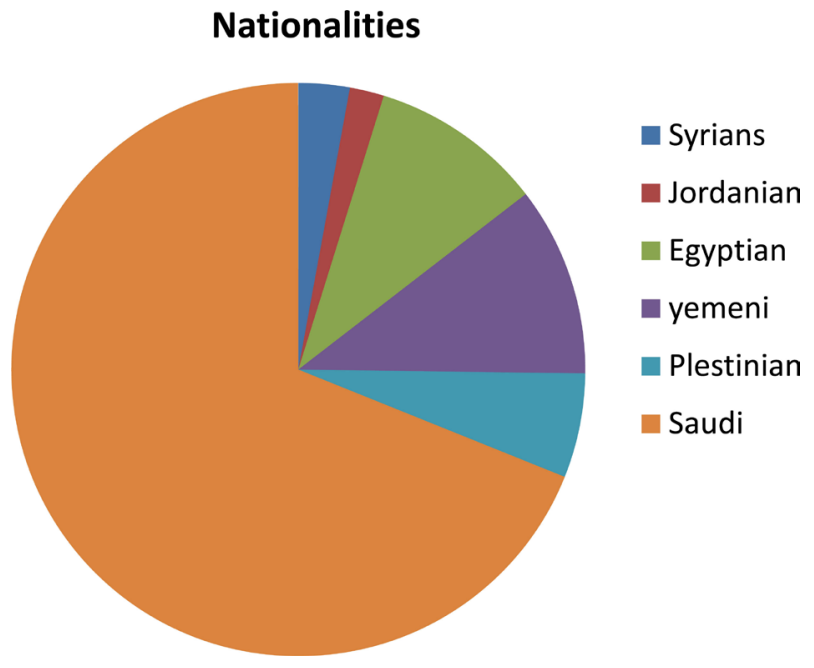

Figure 1. Nationalities.

\begin{tabular}{lrc}
\hline & Patient's Characteristic & Percentage \\
\hline 1 & Pre-menopausal & $43.6 \%$ \\
2 & Post-menopausal & $56.4 \%$ \\
3 & Previous axillary surgery & $3.7 \%$ \\
4 & Radiological evaluation of axilla & $68.2 \%$ \\
5 & Lumpectomy + SLNB & $96.4 \%$ \\
6 & Lumpectomy + ALND & $1.8 \%$ \\
7 & Unspecified BCS & $1.8 \%$ \\
8 & Neo-adjuvant chemotherapy & $3.6 \%$ \\
9 & Adjuvant chemotherapy & $80 \%$ \\
10 & Intra-operative radiotherapy & $29.1 \%$ \\
11 & Lympho-vascular margins positive & $20.9 \%$ \\
\hline
\end{tabular}

Figure 2. General characteristics of Patients.

right breast in $40 \%$ of cases. Upper outer quadrant was involved in majority of cases $(51.9 \%)$, upper inner quadrant in $13.9 \%$, retro-areolar in $12.7 \%$, lower inner quadrant in $6.4 \%$, lower outer in $3.6 \%$, supra-areolar in $1.8 \%$, and infraareolar in $0.9 \%$ (Figure 3). In our study size of breast mass was mostly between 1 $-2.9 \mathrm{~cm}$ (43.5\%), 13\% had mass between $3-4 \mathrm{~cm}$, more than $4 \mathrm{~cm}$ was found in $10.2 \%$ and subcentimetric was $14.5 \%$ (Figure 4 ). There was history of previous axillary surgery in minority of cases (3.7\%). Pre-operative assessment by radiology was done in most of cases (68.2\%).

Most of our patients underwent Lumpectomy plus sentinel lymph node biopsy (96.4\%). Lumpectomy and axillary lymph node dissection was done in minority of cases (1.8\%), and unspecified Breast

Conservation Surgery was performed in $1.8 \%$. Most of our patients received adjuvant chemotherapy (80\%), while neo-adjuvant chemotherapy was given in $3.6 \%$ of cases. Gross margins were positive in $17.3 \%$ which were recognized in 


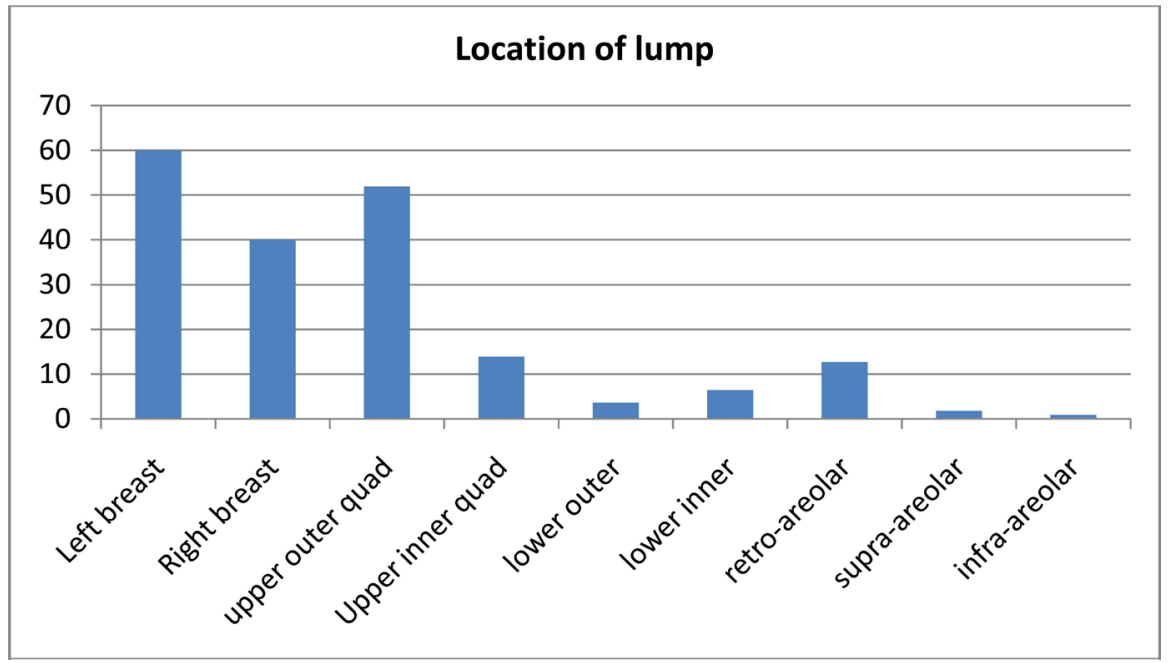

Figure 3. Location of lump.

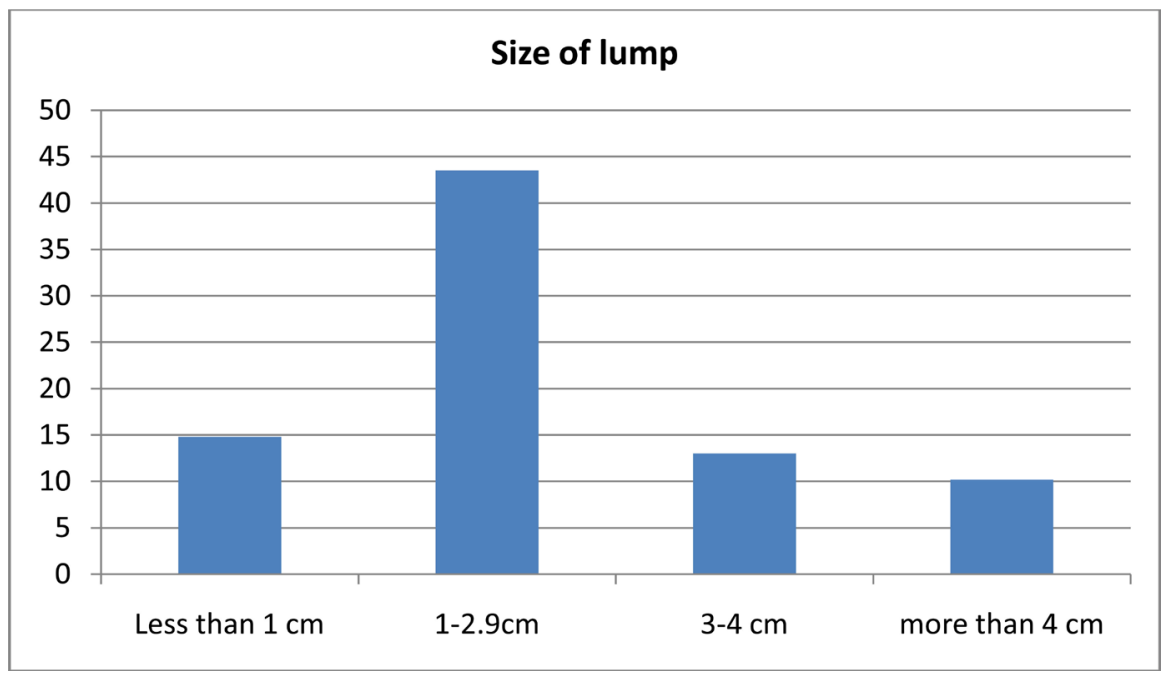

Figure 4. Size of lump.

operating room. After lumpectomy breast mass was sent for frozen section analysis of margins which were found positive for malignancy in $28.2 \%$ of cases. A rim of tissue of the cavity was shaved and sent for frozen section again to confirm complete excision of malignant mass. These tissue showed new margins positive for malignancy on frozen section in 3.6\% of cases. Most of cases were found negative for malignancy in frozen section $(79.1 \%)$ in re-lumpectomy tissue. Permanent section histology showed positive margins in $5.5 \%$ of cases who were negative in frozen section. Permanent section negative margins were however in majority of patients (94.5\%) (Figure 5). Re-operation of patients who were positive on permanent section was done in $7.3 \%$. Intra-operative radiotherapy was done in $29.1 \%$. Most of our patients underwent sentinel Lymph node biopsy (98.2\%). More than two sentinel lymph nodes were retrieved in majority of cases.SLN on frozen section were found positive for malignancy in $25.5 \%$, while on permanent section they were positive in $38.2 \%$. Completion axillary dissection was done in $34.5 \%$. 
Histopathology was studied and showed that majority were invasive ductal carcinoma (77.3\%), DCIS in 10\%, invasive lobular carcinoma in $7.3 \%$, mucinus in $2.7 \%$, medullary in $0.9 \%$, LCIS in $0.9 \%$ cases (Figure 6 ). Lympho-vascular margins were positive in $20.9 \%$. ER were positive in $69.1 \%$, PR were positive in $60 \%$. HER-2 were positive in $26.4 \%$ cases (Figure 7 ). Most of tumor were T1 and T2 $(42.7 \%, 42.7 \%)$, and rest were T3 and T4. Carcinoma in situ was found in $6.4 \%$ cases. Majority were axillary lymph nodes negative (60.9\%), followed by N1 (33.63\%), N2-4.5\%. Majority of our cases were non metastatic (98.2\%), while MI only $0.9 \%$. Post-operative complications were assessed and skin necrosis was found in $2.2 \%$, numbness in $4.4 \%$, and wound infection was in $2.2 \%$ (Figure 8 ).

\section{Discussion}

Advent of breast conserving surgery has dramatically decreased mastectomies. Lumpectomy margins are subject of debate as how much safety margin is safe.

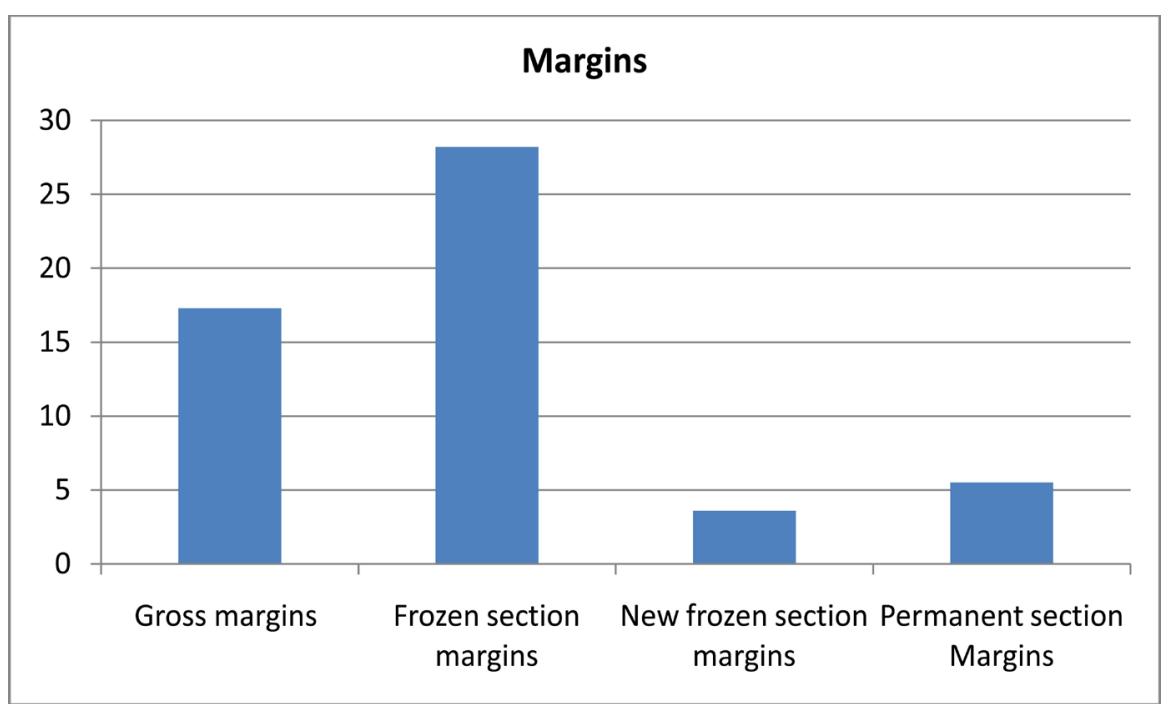

Figure 5. Lumpectomy Positive margins \%.

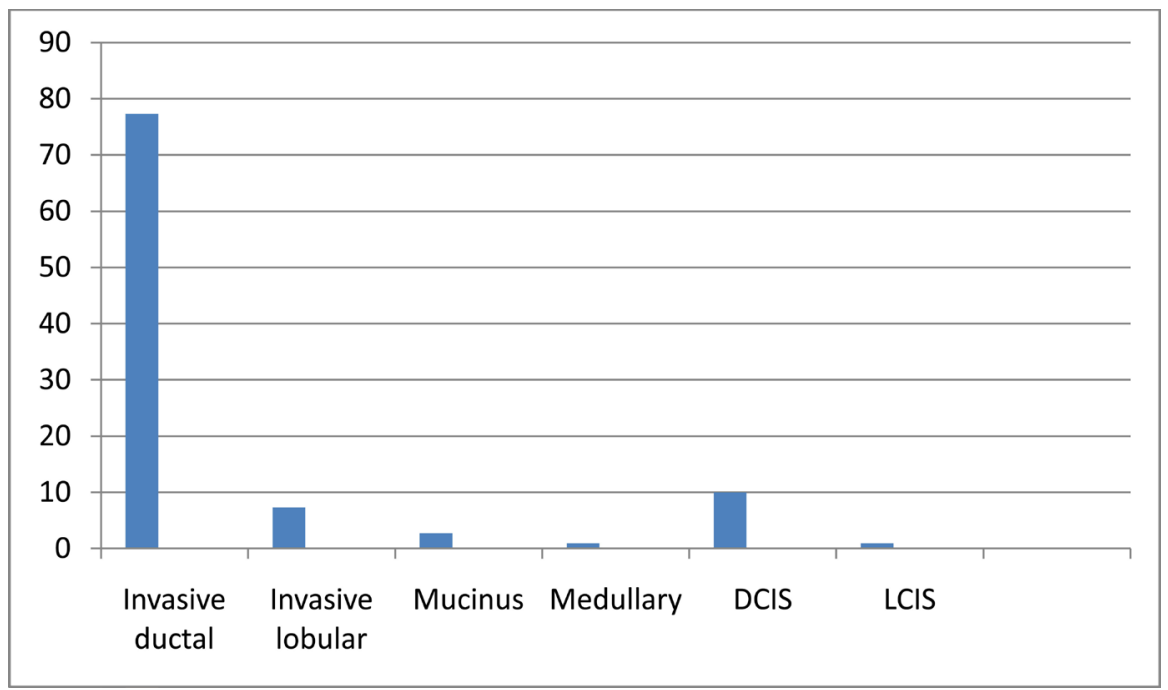

Figure 6. Histopathology. 


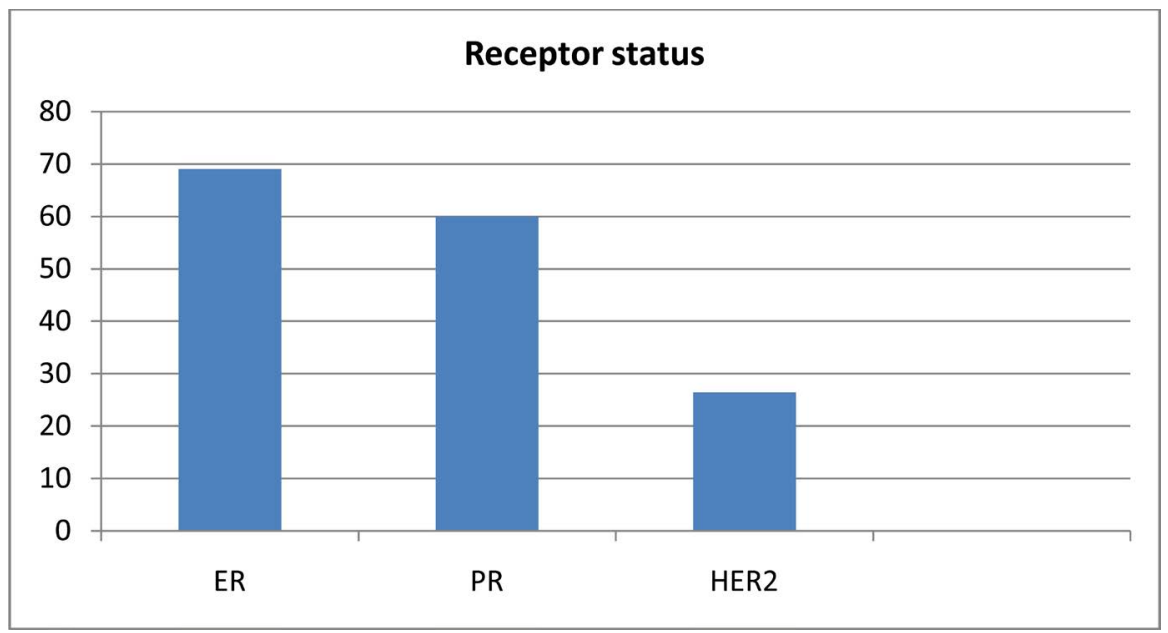

Figure 7. Receptors status.

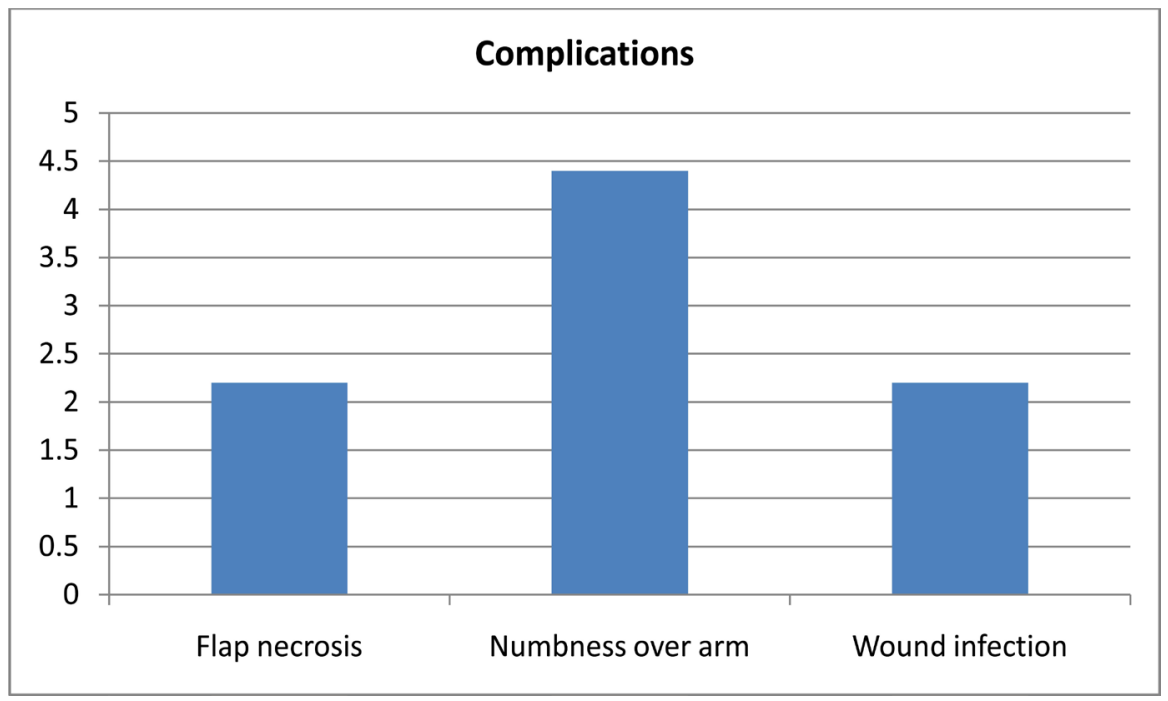

Figure 8. Complications.

American society of breast surgeons recommends that if all margins are ink negative and more than $1 \mathrm{~mm}$, then no surgery is required [17]. Lumpectomy margins are major determinant of local recurrence. Other than surgical margins, factors like age, tumor stage, grade of tumor and molecular characteristics do play important role in recurrence. National Comprehensive Cancer Network [NCCN] also recommends that if inked margins are negative for invasive cancer then no further surgery is required [18]. For DCIS accepted negative margin is more than $10 \mathrm{~mm}$. Meta-analysis showed that margin more than $10 \mathrm{~mm}$ has decreased local recurrence in relation to $2 \mathrm{~mm}$ margins with or without radiotherapy [19]. Per-operative tools to assess margins used are wire guided localization, radiosurgery, intra-operative ultrasound guided resection, specimen radiography, cryoprobe-assisted lumpectomy (CAL), light-guided lumpectomy, and haematoma-directed ultrasound guided (HUG) localization.

Positive margins on final specimen were $25 \%$ in study by Feron et al. [20] and similar in other studies [6] [21] [22] [23]. Re-excision rate ranges from $23 \%$ to 
59\% [10] [11] [12] and some reports more than 50\% [24] [25] but our re-excision rate is $28 \%$ which is similar to Uecker et al. [26]. Completion mastectomy rate is $14 \%$ [27]. Osborn et al. reported that patient who underwent lumpectomy without frozen section analysis had re-operation rate of $15 \%-50 \%$ while those who had frozen section at time of lumpectomy had re-operation rate of $3 \%$ [28]. Our re-operation rate with frozen section analysis was 5.5\%. Frozen section analysis of lumpectomy margins avoided re-operation and so saved patients from morbidity and recurrence. Permanent section analysis showed margins positive for malignancy in $5.5 \%$ of cases in our patients. Frozen section analysis of lumpectomy margins helped in reducing positive margins of $38.2 \%$ to $5.5 \%$ finally in permanent section.

To avoid re-excision which carry additional morbidity, there is a talk by some surgeons to perform cavity shaving [24] [29]. Recurrence rate is inversely related with the distance of tumor foci from ink margin [5]. Macrosopically it is difficult to distinguish tumor cells on lumpectomy margins, so frozen section analysis is an indispensible tool for complete excision of tumor. Incorporating routine frozen section analysis of breast lumpectomy margins in surgical practice will avoid complications and recurrence of disease.

\section{Conclusion}

Frozen section of breast lumpectomy margins is an indispensable step in breast conservation surgery as it decreases recurrence and re-operation rate.

\section{Conflict of Interest}

Authors have no conflict of interest.

\section{References}

[1] Fisher, B., Anderson, S., Bryant, J., Margolese, R.G., Deutsch, M., Fisher, E.R., et al. (2002) Twenty-Year Follow-Up of a Randomized Trial Comparing Total Mastectomy, Lumpectomy, and Lumpectomy plus Irradiation for the Treatment of Invasive Breast Cancer. The New England Journal of Medicine, 347, 1233-1241. https://doi.org/10.1056/NEJMoa022152

[2] Veronesi, U., Cascinelli, N., Mariani, L., Greco, M., Saccozzi, R., Luini, A., et al. (2002) Twenty-Year Follow-Up of a Randomized Study Comparing Breast-Conserving Surgery with Radical Mastectomy for Early Breast Cancer. The New England Journal of Medicine, 347, 1227-1232. https://doi.org/10.1056/NEJMoa020989

[3] Mullen, R., Macaskill, E.J., Khalil, A., Elseedawy, E., Brown, D.C., Lee, A.C., et al. (2012) Involved Anterior Margins after Breast Conserving Surgery: Is Re-Excision Required? European Journal of Surgical Oncology, 38, 302-306.

[4] Laucirica, R. (2005) Intraoperative Assessment of the Breast-Guidelines and Potential Pitfalls. Archives of Pathology \& Laboratory Medicine, 129, 1565-1574.

[5] Singletary, S.E. (2002) Surgical Margins in Patients with Early-Stage Breast Cancer Treated with Breast Conservation Therapy. The American Journal of Surgery, 184, 383-393.

[6] Lovrics, P.J., Cornacchi, S.D., Farrokhyar, F., Garnett, A., Chen, V., Franic, S., et al. (2009) The Relationship between Surgical Factors and Margin Status after Breast 
Conservation Surgery for Early Stage Breast Cancer. The American Journal of Surgery, 197, 740-746.

[7] Acosta, J.A., Greenlee, J.A., Gubler, K.D., Goepfert, C.J. and Ragland, J.J. (1995) Surgical Margins after Needle-Localization Breast Biopsy. The American Journal of Surgery, 170, 643-645.

[8] Gajdos, C., Tartter, P.I., Bleiweiss, I.J., Hermann, G., de Csepel, J., Estabrook, A., et al. (2002) Mammographic Appearance of Nonpalpable Breast Cancer Reflects Pathologic Characteristics. Annals of Surgery, 235, 246-251.

https://doi.org/10.1097/00000658-200202000-00013

[9] Papa, M.Z., Klein, E., Davidson, B., Karni, T., Sperber, F., Koller, M., et al. (1996) The Effect of Anesthesia Type on Needle Localization Breast Biopsy: Another Point of View. The American Journal of Surgery, 171, 242-243.

[10] McCahill, L.E., Single, R.M., Aiello Bowles, E.J., Feigelson, H.S., James, T.A., Barney, T., et al. (2012) Variability in Re-Excision Following Breast Conservation Surgery. JAMA, 307, 467-475. https://doi.org/10.1001/jama.2012.43

[11] Freedman, G., Fowble, B., Hanlon, A., Nicolaou, N., Fein, D., Hoffman, J., et al. (1999) Patients with Early Stage Invasive Cancer with Close or Positive Margins Treated with Conservative Surgery and Radiation Have an Increased Risk of Breast Recurrence That Is Delayed by Adjuvant Systemic Therapy. International Journal of Radiation Oncology, Biology, Physics, 44, 1005-1015.

[12] Waljee, J.F., Hu, E.S., Newman, L.A. and Alderman, A.K. (2008) Predictors of Re-Excision among Women Undergoing Breast-Conserving Surgery for Cancer. Annals of Surgical Oncology, 15, 1297-1303. https://doi.org/10.1245/s10434-007-9777-x

[13] Veronesi, U., Cascinelli, N., Mariani, L., et al. (2002) Twenty Year Follow-Up of a Randomized Study Comparing Breast Conserving Surgery with Radical Mastectomy for Early Breast Cancer. The New England Journal of Medicine, 347, 1227-1232. https://doi.org/10.1056/NEJMoa020989

[14] Fisher, B., Anderson, S., Bryant, J., et al. (2002) Twenty-Year Follow-Up of a Randomized Trial Comparing Total Mastectomy, Lumpectomy, and Lumpectomy plus Irradiation for the Treatment of Invasive Breast Cancer. The New England Journal of Medicine, 347, 1233-1241. https://doi.org/10.1056/NEJMoa022152

[15] Houssami, N., Macaskill, P., Marinovich, M.L., et al. (2010) Meta Analysis of the Impact of Surgical Margins on Local Recurrence in Women with Early-Stage Invasive Breast Cancer Treated with Breast-Conserving Therapy. The European Journal of Cancer, 46, 3219-3232.

[16] Groot, G., Rees, H., Pahwa, P., Kanagaratnam, S. and Kinloch, M. (2011) Predicting Local Recurrence Following Breast-Conserving Therapy for Early Stage Breast Cancer: The Significance of a Narrow $(</=2 \mathrm{~mm})$ Surgical Resection Margin. Journal of Surgical Oncology, 103, 212-216. https://doi.org/10.1002/jso.21826

[17] American Society of Breast Surgeons. Position Statement on Breast Cancer Lumpectomy Margins.

https://www.breastsurgeons.org/statements/PDF_Statements/Lumpectomy_Margin s.pdf

[18] National Comprehensive Cancer Network. Breast Cancer (Version 1.2014). http://www.nccn.org/professionals/physician_gls/pdf/breast.pdf

[19] Wang, S.Y., Chu, H., Shamliyan, T., Jalal, H., Kuntz, K.M., Kane, R.L., et al. (2012) Network Meta-Analysis of Margin Threshold for Women with Ductal Carcinoma in Situ. Journal of the National Cancer Institute, 104, 507-516. https://doi.org/10.1093/jnci/djs142 
[20] Feron, J.-G., Nguyen, A., Bézu, C., Antoine, M., Darai, E., Coutant, C., Rouzier, R. and Uzan, S. (2011) Interest in Cavity Shaving in Breast Conservative Treatment Does Not Depend on Lumpectomy Technique. Breast, 20, 358-364.

[21] Leong, C., Boyages, J., Jayasinghe, U.W., Bilous, M., Ung, O., Chua, B., et al. (2004) Effect of Margins on Ipsilateral Breast Tumor Recurrence after Breast Conservation Therapy for Lymph Node-Negative Breast Carcinoma. Cancer, 100, 1823-1832. https://doi.org/10.1002/cncr.20153

[22] Jacobson, A.F., Asad, J., Boolbol, S.K., Osborne, M.P., Boachie-Adjei, K. and Feldman, S.M. (2008) Do Additional Shaved Margins at the Time of Lumpectomy Eliminate the Need for Re-Excision? The American Journal of Surgery, 196, 556558.

[23] Besana-Ciani, I. and Greenall, M.J. (2008) The Importance of Margins Status after Breast Conservative Surgery and Radiotherapy in Node Positive Patients: A Follow-Up of 10-15 Years. International Seminars in Surgical Oncology, 5, 13. https://doi.org/10.1186/1477-7800-5-13

[24] Barthelmes, L., Al Awa, A. and Crawford, D.J. (2003) Effect of Cavity Margin Shavings to Ensure Completeness of Excision on Local Recurrence Rates Following Breast Conserving Surgery. European Journal of Surgical Oncology, 29, 644-648.

[25] Huston, T.L., Pigalarga, R., Osborne, M.P. and Tousimis, E. (2006) The Influence of Additional Surgical Margins on the Total Specimen Volume Excised and the ReOperative Rate after Breast-Conserving Surgery. The American Journal of Surgery, 192, 509-512.

[26] Uecker, J.M., Bui, E.H., Foulkrod, K.H. and Sabra, J.P. (2011) Intraoperative Assessment of Breast Cancer Specimens Decreases Cost and Number of Reoperations. The American Surgeon, 77, 342-344.

[27] O’Donnell, M.E., Salem, A., Badger, S.A., Sharif, M.A., Lioe, T. and Spence, R.A. (2008) Completion Mastectomy after Breast Conserving Surgery. Breast, 17, 199204.

[28] Osborn, J.B., Keeney, G.L., Jakub, J.W., Degnim, A.C. and Boughey, J.C. (2011) Cost-Effectiveness Analysis of Routine Frozen-Section Analysis of Breast Margins Compared with Reoperation for Positive Margins. Annals of Surgical Oncology, 18, 3204-3209. https://doi.org/10.1245/s10434-011-1956-0

[29] Tengher-Barna, I., Hequet, D., Reboul-Marty, J., Frassati-Biaggi, A., Seince, N., Rodrigues-Faure, A., et al. (2008) Prevalence and Predictive Factors for the Detection of Carcinoma in Cavity Margin Performed at the Time of Breast Lumpectomy. Modern Pathology, 22, 299-305. https://doi.org/10.1038/modpathol.2008.186 
Submit or recommend next manuscript to SCIRP and we will provide best service for you:

Accepting pre-submission inquiries through Email, Facebook, LinkedIn, Twitter, etc. A wide selection of journals (inclusive of 9 subjects, more than 200 journals)

Providing 24-hour high-quality service

User-friendly online submission system

Fair and swift peer-review system

Efficient typesetting and proofreading procedure

Display of the result of downloads and visits, as well as the number of cited articles Maximum dissemination of your research work

Submit your manuscript at: http://papersubmission.scirp.org/

Or contact ss@scirp.org 